\title{
Frequency of RANTES gene
} polymorphisms and their association with incidence of malaria: a longitudinal study
on children in Iganga district, Uganda

Catherine N. Lwanira ${ }^{1 *}$, Mark Kaddu Mukasa ${ }^{2}$, Göte Swedberg ${ }^{3 \dagger}$ and Fred Kironde ${ }^{1,4 \dagger}$

\begin{abstract}
Background: The severity and outcome of malaria is influenced by host immunity in which chemokines such as Regulated upon Activation, Normal T cell Expressed and Secreted (RANTES) play an important role. Previous studies show that variations in the RANTES gene affect RANTES protein production, hence altering host immunity. In this study, the relationship between presence of mutations in RANTES and incidence of malaria in a cohort of children living in a malaria-endemic area of Uganda was determined.
\end{abstract}

Methods: This was a longitudinal study comprising of 423 children aged between 6 months and 9 years, who were actively followed up for 1 year. Malaria episodes occurring in the cohort children were detected and the affected children treated with national policy drug regimen. Mutations in the RANTES gene were determined by PCR-RFLP method and their frequencies were calculated. A multivariate negative binomial regression model was used to estimate the impact of RANTES mutations on malaria incidence. In all statistical tests, a P-value of $<0.05$ was considered as significant.

Results: The frequencies of the $-403 \mathrm{~A}$ and $\ln 1.1 \mathrm{C}$ allele were 53.7 and $19.2 \%$, respectively. No mutations were found at the -28 locus. After adjustment of incidence rates for age, blood group, insecticide-treated bed net (ITN) use, malaria history and the sickle cell trait, $1 \mathrm{n} 1.1 \mathrm{~T} / \mathrm{C}$ heterozygotes and homozygotes showed a non-significant trend towards higher incidence rates compared to wild-type individuals (IRR $=1.10 ; \mathrm{P}=0.55$ and $I R R=1.25 ; \mathrm{P}=0.60$, respectively). Similarly, there was no significant difference in malaria incidence rates between RANTES - 403G/A heterozygotes or homozygotes and those without mutations (IRR $=1.09 ; \mathrm{P}=0.66$ and $I R R=1.16 ; \mathrm{P}=0.50$, respectively). No relation was seen between RANTES polymorphisms, baseline parasite densities and the time to first re-infection after administration of anti-malaria drugs.

Conclusions: This study showed that the $-403 \mathrm{~A}$ mutation occurs in nearly half of the study population and the In1.1C allele occurs in one in every four children. Despite the high frequency of these mutations, there was no clear association with malaria incidence. Other studies evaluating more markers, that could potentially modulate RANTES gene transcription alongside other genetic modifiers of malaria susceptibility, may provide further explanations to these less dramatic findings.

Keywords: RANTES gene polymorphisms, Plasmodium falciparum malaria, Incidence

\footnotetext{
*Correspondence: clwanira@gmail.com

${ }^{\dagger}$ Göte Swedberg and Fred Kironde contributed equally to this work

' School of Biomedical Sciences, College of Health Sciences, Makerere

University, PO Box 7072, Kampala, Uganda

Full list of author information is available at the end of the article
} 


\section{Background}

Plasmodium falciparum malaria accounts for approximately 198 million clinical cases of malaria worldwide and 584,000 deaths annually [1]. A majority of these deaths occur in sub Saharan Africa, with over $78 \%$ of all deaths happening in children under 5 years of age [1]. The development of naturally acquired immunity takes time and is associated with increasing age, which correlates with a reduction in mortality rates arising from severe forms of $P$. falciparum infection [2]. The development of this immunity still remains a mystery and as to why malaria episodes occur more frequently in some children compared to others raises further questions. Host genetic factors play an important role in reducing the risk to Plasmodium infection. The protective effect of the sickle cell trait (Hb AS) against both uncomplicated and severe malaria disease has been well documented [3-8]. It is, therefore, important to examine different host factors in order to further define their association with $P$. falciparum infection.

Regulatory cytokines and other mediators have also been reported to play a critical role in controlling parasitaemia and subsequent elimination of infection. Interferon-gamma (IFN $\gamma$ ), tumor necrosis factor (TNF), Interleukin 10 (IL-10), IL-17, IL-4, C-C chemokine RANTES (Regulated upon Activation, Normal $\mathrm{T}$ cell Expressed and Secreted), matrix metalloproteinases 8 (MMP8s) and tissue inhibitor of metalloproteinases 1 (TIMP1) have been linked to disease severity in malariainfected individuals [9-16]. The mechanism of this immune modulation involves activation of leukocytes, recruitment of leukocytes and Plasmodium-infected erythrocytes causing occlusion of blood vessels, degradation of cell-cell junctions, blood-brain barrier dysfunction, interfering with formation of blood vessels and formation of blood cells or haematopoiesis [11, 12, 1721]. Previous studies have shown that variations in the RANTES gene affect RANTES protein production and the subsequent host immune response towards a variety of infections [22, 23]. Low levels of the RANTES protein have also been observed in severe malaria due to acquisition of Plasmodium haemozoin by monocytes [24] or malaria-induced thrombocytopaenia [11] and have been associated with mortality among children with cerebral malaria [12].

The human RANTES gene is located on chromosome 17q11.2-q12, has a genomic size of $8.8 \mathrm{~kb}$ and encodes a protein of $8 \mathrm{kDa}$ [22]. Among the several single nucleotide polymorphisms (SNPs) in the RANTES gene that have been reported before, the $-403 \mathrm{G} / \mathrm{A}$ and the $-28 \mathrm{C} / \mathrm{G}$ nucleotides located in the promoter region, along with the InI.1T/C present in the first intron, are the most polymorphic and appear to modify RANTES transcription [22]. The RANTES - 28G variant was found to up-regulate RANTES expression in vitro [22, 23] and to be associated with delayed disease progression among HIV-infected adults [23, 25-27]. The In1.1C variant, which also occurs in strong linkage disequilibrium with -403 A allele, was associated with reduced RANTES transcription activity in vitro [22] and increased rate of AIDS progression $[22,28,29]$, but was found to be protective against disease progression among Ugandan HIV adults [30]. The prevalence of these RANTES polymorphisms varies in different populations. The $-403 \mathrm{~A}$ allele occurs predominantly among African populations [22, $28,30]$, while the $-28 \mathrm{G}$ allele is found to be more prevalent among Japanese [31] and Han Chinese populations [23], but scarcely distributed among Caucasians and African populations $[22,30]$. RANTES levels were also found to vary by race with low values prevailing among African populations compared to Caucasians [32].

In several other studies, RANTES polymorphisms have been shown to affect the course of systemic lupus erythematosus [33], asthma [34], atopic dermatitis [35, 36], diabetic nephropathy [37], coronary artery disease [38], recurrent acute rejection [39], and sickle cell anaemia [40]. However, little is known of their role in malaria. Since these variants have been shown to modify RANTES protein expression and low levels of RANTES have been implicated in malaria, this study was designed to determine the relation between these variants and the incidence of malaria among children living in an endemic area. Accordingly, the aim of this study was (1) to determine the allelic and genotype prevalences of RANTES gene polymorphisms, namely $-403 \mathrm{G} / \mathrm{A},-28 \mathrm{C} / \mathrm{G}$ and In1.1T/C in a population of children from a malariaendemic area (Iganga, Uganda); and, (2) to investigate the relationship between these polymorphisms with malaria incidence, parasite densities upon malaria diagnosis and the length of time to first re-infection following curative malaria treatment in this children's cohort.

\section{Methods}

\section{Study design and setting}

This was a longitudinal study carried out in villages of Iganga district where children aged 6 months to 9 years were enrolled in order to determine malariometric indices during September 2008 and November 2009 towards preparation for the GMZ2 phase II malaria vaccine trial. From September 2008 to October 2008, a team of experienced home visitors approached households to systematically recruit children into the baseline study. Eligible children were enrolled into the study and followed up for a period of 1 year from November 2008 to November 2009. Iganga district is situated in south-eastern Uganda, about $25 \mathrm{~km}$ to the north of Lake Victoria and lies at an 
altitude of about $1138 \mathrm{~m}$ above sea level at latitude: $00^{\circ} 36^{\prime}$ North and longitude: $33^{\circ} 30^{\prime}$ East. Malaria transmission is this area is holo-endemic (intense and perennial), with transmission peaks seen following the major rains, which normally occur between April to June and September to December [41]. The annual entomological inoculation rate (EIR) is not known, but is estimated to be 562 infective bites per person per year in the neighbouring district of Tororo [42]. The study cohort was recruited from a community living within six villages of Iganga district that are in close proximity to the malaria study clinic located at Makerere University Iganga/Mayuge Demographic Surveillance Site (MaK-DSS). No interventional studies were undertaken in this study area at the time this study cohort was assembled. Inclusion criteria of cohort study were as follows; (1) age 6 months to 9 years; (2) agreement to come to study clinic for any febrile episode or illness; (3) agreement to avoid medications administered outside the study; (4) agreement to remain in study area during the twelve months follow up; (5) absence of known chronic disease and (6) written informed consent provided by parent or guardian. Severely malnourished children (below $-3 \mathrm{z}$ scores of the median WHO growth standards) [43] were excluded. Follow-up started when children fulfilled all of the selection criteria and were free of symptomatic malaria. The villages were divided by convenience into active (nearby) villages and passive (more remote) villages.

\section{Clinical assessment and determination of malaria incidence}

A baseline survey was carried out and eligible children were enrolled into this cohort. At the time of enrolment, a physical examination was performed by study physicians. Baseline demographic data were collected from guardians through a questionnaire-based interview, including malariometric indices. After the baseline survey, parents or guardians were instructed to bring their children to the malaria clinic based at Iganga Hospital whenever they felt unwell so as to avoid using any drugs not administered or approved by a study physician. A team of field workers visited the enrolled children at home every fortnight. Those children found unwell were referred to the clinic for care or referral in case of severe illness. Malaria was defined as any $P$. falciparum parasitaemia plus a tympanic temperature of $\geq 38.0^{\circ} \mathrm{C}$ or a history of fever (within the past $48 \mathrm{~h}$ ). Thick and thin peripheral blood slides were stained with Giemsa and examined under a microscope. Parasite densities were calculated by counting the number of asexual parasites per 200 white blood cells (WBC) and assuming a WBC count of $8000 / \mu \mathrm{L}$ blood [44]. In addition, approximately $2 \mathrm{ml}$ of blood sample were drawn and mixed with ethylenediaminetetracetic acid (EDTA) anticoagulant for subsequent analysis of DNA. Severe malaria was defined as having hyper parasitaemia $(>5 \%$ parasitized erythrocytes or $>250,000$ parasites $/ \mu \mathrm{L}$ ) and any of the danger signs including a core body temperature $>40{ }^{\circ} \mathrm{C}$, severe anaemia (haemoglobin $<5 \mathrm{~g} / \mathrm{dl}$ ), hyper bilirubinemia (total bilirubin $>2.5 \mathrm{mg} / \mathrm{dl}$ ), prostration or weakness, impaired consciousness, respiratory distress, hypoglycaemia (blood sugar $<40 \mathrm{mg} / \mathrm{dL}$ ), acidosis, cerebral malaria or other additional sign as specified in definition for severe malaria $[45,46]$. Children with confirmed malaria were treated with artemether-lumefantrine $\left(\right.$ Coartem $\left.^{\circledR}\right)$ according to the national treatment guidelines and those with severe malaria were admitted for care at Iganga Hospital acute care unit. Time at risk for new infection was considered as the duration of study participation excluding 14 days after each episode of malaria.

\section{Genomic DNA isolation}

Genomic DNA was extracted from blood leukocytes using E.Z.N.A Blood DNA kit as outlined by the manufacturer's protocol (Omega Bio-tek, USA). Approximately $0.1 \mu \mathrm{g}$ of genomic DNA was used for the genotyping assays.

\section{Detection of RANTES gene polymorphisms}

Polymorphisms were detected using polymerase chain reaction (PCR) amplification followed by restriction endonuclease digestion (RFLP) as described elsewhere $[23,47,48]$. For each reaction, $1-2 \mu \mathrm{L}$ of the extracted DNA sample was incubated with DreamTaq DNA polymerase (Thermo scientific Inc, USA), $0.5 \mu \mathrm{M}$ of each primer, $100 \mu \mathrm{M}$ dNTPs and $2.0 \mathrm{mM} \mathrm{MgCl}$. After firstround PCR, about $5 \mu \mathrm{L}$ of each reaction was digested with restriction endonucleases and products were subjected to electrophoresis on $2.5 \%$ agarose gels (Thermo scientific Inc, USA) and visualized with ethidium bromide. Genotypes were assessed by comparing the sizes of reaction products and controls after digestion.

\section{Sickle cell genotyping}

Sickle cell genotyping was based on characterization of haemoglobin AS (Hb AS) using nested PCR followed by RFLP as previously described by Parikh et al. [49]. In the first round, approximately $1-2 \mu \mathrm{L}$ of the extracted DNA was incubated with DreamTaq DNA polymerase (Thermo scientific Inc, USA), $0.1 \mu \mathrm{M}$ of each primer, $200 \mu \mathrm{M}$ dNTPs and $2.0 \mathrm{mM} \mathrm{MgCl} \mathrm{MCR}_{2}$.Products from the first round were subjected to a second amplification using DreamTaq DNA polymerase (Thermo scientific Inc, USA), $0.05 \mu \mathrm{M}$ of each primer, $200 \mu \mathrm{M}$ dNTPs and $2.0 \mathrm{mM} \mathrm{MgCl}_{2}$. After second-round PCR, products were digested with restriction endonucleases and subjected to 
electrophoresis on $2.5 \%$ agarose gels (Thermo scientific Inc, USA) containing ethidium bromide. As described above, genotypes were assessed by comparing the sizes of reaction products and controls after digestion.

\section{Data management and analysis}

Data were cleaned, coded and entered into Microsoft Office Access ${ }^{\text {TM }}$ 2007. Descriptive statistics, Chi square tests and multivariate analysis were carried out using Stata12.0 (Stata Corp, College Station, TX, USA). Allele and genotype frequencies were calculated in accordance with the Hardy-Weinberg principle [50]. The association between RANTES genotype and malaria incidence was estimated using a multivariate negative binomial regression model. Initially, a bivariate analysis was performed to determine the relationship between each demographic/ clinical characteristic and malaria incidence. The final multivariate analysis model included the RANTES genotype and all identified predictors of malaria incidence (age, malaria history, ITN use and the sickle cell trait). Adjusted incidence rates ratios (IRRs), P values and $95 \%$ confidence intervals were calculated. The Wilcoxon rank sum test was used to compare the distribution of parasite densities across the different RANTES genotypes.

The effect of RANTES polymorphisms on the length of time to first re-infection following administration of anti-malarial drug was estimated using Kaplan-Meier non-parametric survival analysis. The log rank test was used to evaluate differences in the survival times between the different RANTES genotypes. Cox proportion hazard regression model was used to control for other independent predictors of length of time to re infection (age, malaria history and ITN use) and adjusted hazard ratios (aHRs) were calculated. For all statistical tests, two-sided $p$ values of less than 0.05 were assumed to show statistical significance.

\section{Ethical considerations}

The clinical study and all study protocols were approved by the School of Medicine Research and Ethics Committee of the College of Health Sciences, Makerere University and by the Uganda National Council for Science and Technology (approval number HS 765). All participants provided written informed consent. All children received appropriate treatment for other attendant medical conditions.

\section{Results}

\section{Study population}

A total of 980 children were screened for baseline studies to determine malariometric indices at Makerere University Iganga-Mayuge Demographic study site, Iganga Hospital during September 2008 and November 2009 (Fig. 1)

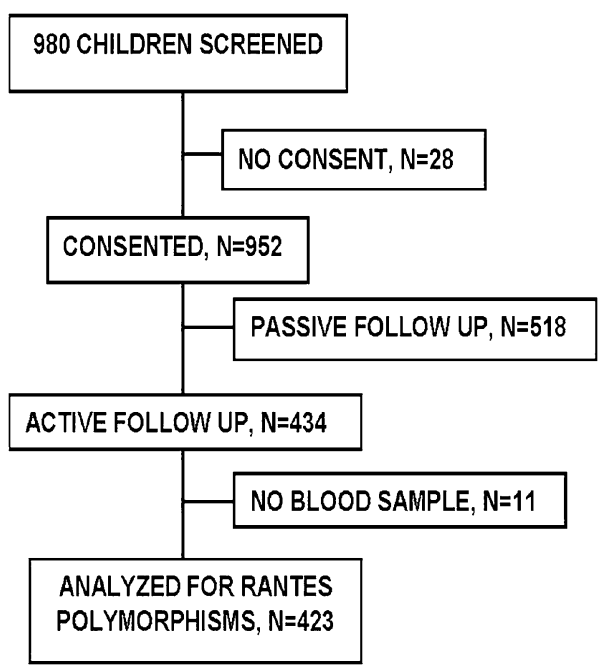

Fig. 1 Participant flow chart. Figure showing the 423 children recruited and actively followed-up who provided samples for RANTES gene polymorphisms analysis

towards preparation for the GMZ2 phase II malaria vaccine trial (Fig. 1). Twenty-eight children were excluded because of guardian unwillingness to participate in the follow-up study. A sample of 434 for each arm was estimated based on assumptions of malaria incidence of $15 \%$ in the active arm, with $95 \%$ confidence interval, and ability to detect a vaccine efficacy of $30 \%$. However, assuming $20 \%$ loss to follow up in the passive arm, a total sample of 518 was considered. Accordingly, of the remaining 952 children, 518 (54.4\%) were monitored passively and 434 (45.6\%) were followed up by active surveillance for 1 year and the incidence of malaria per child was determined. Eleven of the 434 children $(2.5 \%)$ would not provide an adequate blood sample for subsequent analysis of DNA. In order to determine the association between RANTES polymorphisms and malaria incidence, only 423 children who had been actively followed-up were included in this study. The majority of study participants $(96.7 \%)$ were of Basoga ethnic background, while the rest constituted other tribes. Baseline characteristics were as follows: mean age, 3.9 years $(\mathrm{SD} \pm 2.3)$; sex, $52.7 \%$ male and $47.3 \%$ female; mean haemoglobin, $12 \mathrm{~g} / \mathrm{dL}(\mathrm{SD} \pm 1.5)$; the predominant blood groups, $\mathrm{O}+(39.4 \%)$ and $\mathrm{B}+(30.4 \%) ; 26.6 \%$ carried the sickle cell trait. A majority of the study participants (94.6\%) reported to have had history of malaria in the 6 months prior to study enrolment, $88.2 \%$ reported to be using an insecticide-treated bed net (ITN) and $95.3 \%$ reported having administered an anti-malarial drug previously (Table 1). No malaria episodes were registered among 217 out of 423 children (51.3\%) after a year of 
Table 1 Demographic and clinical characteristics of the study population

\begin{tabular}{ll}
\hline Age in years (mean, SD) & $3.92 \pm 2.32$ \\
Sex, n (\%) & \\
Male & $223(52.7)$ \\
Female & $200(47.3)$ \\
Weight in kg (mean, SD) & $15.47 \pm 5.21$ \\
Blood group, $\mathrm{n}(\%)$ & \\
O+ & $166(39.4)$ \\
A+ & $96(22.8)$ \\
B+ & $128(30.4)$ \\
AB & $27(6.4)$ \\
Non O (A+ B+ AB + others) & $255(60.6)$ \\
Sickle cell genotype, $\mathrm{n}(\%)$ & \\
Wild type (Hb AA) & $303(73.2)$ \\
Heterozygous (Hb AS) & $110(26.6)$ \\
Homozygous (Hb SS) & $1(0.2)$ \\
Mean haemoglobin, SD (g/dL) & $11.97 \pm 1.46$ \\
Malaria history, $\mathrm{n}(\%)$ & \\
Yes & $400(94.6)$ \\
No & $15(3.5)$ \\
Not sure & $8(1.9)$ \\
Reported ITN use, $\mathrm{n}(\%)$ & \\
Yes & $373(88.2)$ \\
No & $50(11.8)$ \\
Reported previous anti-malarial drug use, $\mathrm{n}(\%)$ & \\
Yes & $403(95.3)$ \\
No & $14(3.3)$ \\
Not sure & $6(1.4)$ \\
\hline
\end{tabular}

longitudinal follow-up. Among those with episodes (206 children), the range was one to nine episodes per child with the distribution as shown in Fig. 2.

\section{Distribution of RANTES polymorphisms}

PCR for genotyping of the three RANTES polymorphic sites was performed for all individuals. The success rate was $96 \%$. Out of the 406 children who were successfully genotyped for the RANTES -403 G/A polymorphism, $224(55.2 \%)$ had the RANTES GA genotype, $26.1 \%$ carried the AA genotype while the remaining (18.7\%) had the wild type genotype. For the In $1.1 \mathrm{~T} / \mathrm{C}$ polymorphisms, only $3.7 \%$ carried homozygous mutations (CC), $30.9 \%$ carried the heterozygous (TC) genotype and a majority $(65.4 \%)$ had the wild-type (TT) genotype. The overall prevalence of the respective markers is shown in Table 2. No polymorphisms at all were seen for the -28 C/G marker. The calculated allele frequencies for -403 G/A and In1.1 T/C polymorphisms were in agreement with earlier reports [22] and the distributions of the genotypes were close to the Hardy-Weinberg equilibrium. The two markers (In1.1 T/C and $-403 \mathrm{G} / \mathrm{A}$ ) showed a clear linkage disequilibrium, all cases with In1.1 mutations also showed -403 mutations (Table 3 ).

\section{Effect of RANTES polymorphisms on malaria incidence and baseline parasite densities}

A single across groups test (ANOVA) was initially performed to determine differences in the distribution of malaria incidence across the RANTES genotypes.

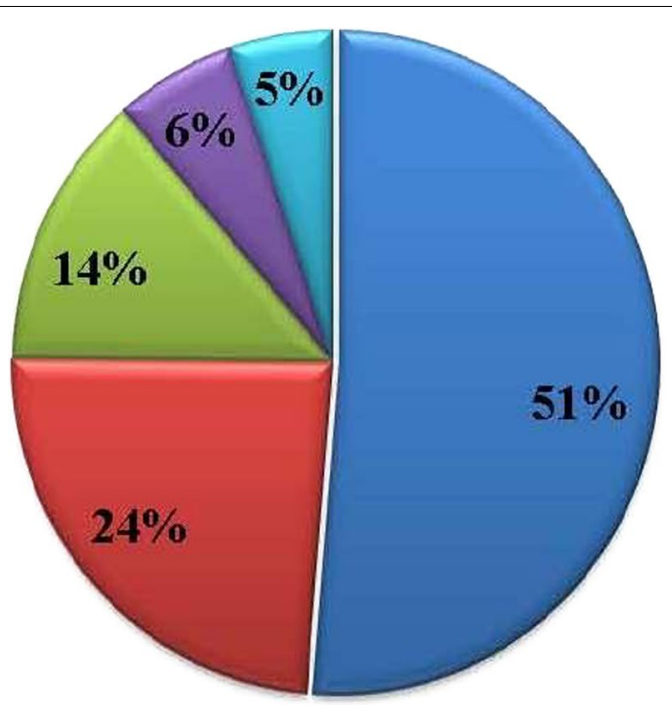

\section{No.of new episodes}

$\square 0 \square 1 \square 2 \square 3 \square 4-9$

Fig. 2 Incidence of malaria among the study participants. $51 \%$ of the study participants had no malaria episodes during the longitudinal followup. $5 \%$ experienced $4-9$ malaria episodes during the follow-up 
Table 2 Genotype and allele frequencies of the RANTES -403G/A, RANTES -28C/G and In 1.1T/C polymorphisms

\begin{tabular}{lll}
\hline $\begin{array}{l}\text { RANTES 403G/A } \\
(n=406)\end{array}$ & $\begin{array}{l}\text { RANTES }-28 C / G \\
(n=403)\end{array}$ & $\begin{array}{l}\text { RANTES In1.1T/C } \\
(n=404)\end{array}$ \\
\hline
\end{tabular}

\begin{tabular}{cccccl}
\hline \multicolumn{5}{c}{ Genotype distribution, $\mathrm{n}(\%)$} \\
GG & $76(18.7)$ & CC & 403 & TT & $264(65.4)$ \\
GA & $224(55.2)$ & CG & 0 & TC & $125(30.9)$ \\
AA & $106(26.1)$ & GG & 0 & CC & $15(3.7)$ \\
\multicolumn{2}{l}{ Allele frequency } & & & & \\
G & 0.46 & C & 1.00 & T & 0.81 \\
A & 0.54 & G & 0.00 & C & 0.19 \\
\hline
\end{tabular}

Table 3 Distribution of RANTES In1.1/403 compound genotypes among the study population

\begin{tabular}{lcc}
\hline RANTES In 1.1/403 genotype & Frequency & Percentage (\%) \\
\hline wt/wt & 75 & 17.8 \\
het/het & 79 & 18.7 \\
het/hom & 42 & 9.9 \\
hom/het & 1 & 0.2 \\
hom/hom & 14 & 3.3 \\
wt/ ${ }^{\text {any }}$ & 212 & 50.1
\end{tabular}

Wt wild type, het heterozygous, hom homozygous

a Any-homozygous or heterozygous
Crude malaria incidence rates/person/year were 0.91 for In1.1T/C wild-type, 0.94 for heterozygous and 0.73 for homozygous individuals. There was no significant difference in the distribution of malaria incidence across the three genotypes $(P=0.76)$. Since there are known predictors of malaria incidence that needed to be adjusted for a multivariate negative binomial regression analysis was done in order to evaluate the association between RANTES polymorphisms and malaria incidence. An initial bivariate (unadjusted) analysis identified age, malaria history, ITN use and sickle cell trait (Table 4) as independent predictors of malaria incidence. After adjusting for the named confounders, the incidence rate for $1 \mathrm{n} 1.1 \mathrm{~T} / \mathrm{C}$ heterozygotes was 1.1 times the incidence rate for wildtype individuals $(\mathrm{P}=0.55)$ and that of homozygotes was 1.25 times the incidence rate for those without mutations $(\mathrm{P}=0.6)$. Median parasite densities were as follows; wild type, 775 [inter quartile range (IQR) 225-2525] parasites/ $\mu \mathrm{L}$; heterozygote, 373 (IQR $150-2250$ ) parasites $/ \mu \mathrm{L}$; homozygote, 2450 (IQR 925-11,000) parasites/ $\mu \mathrm{L}$. There was no difference in the median parasite densities between $1 \mathrm{n} 1.1 \mathrm{~T} / \mathrm{C}$ heterozygotes and wild types $(\mathrm{P}=0.26)$ or homozygotes and wild type individuals $(\mathrm{P}=0.17)$.

For the RANTES -403G/A polymorphism, crude annual malaria incidence rates were 0.83 for wildtype, 1.07 for heterozygotes and 0.97 for homozygous

Table 4 Malaria incidence and other demographic characteristics

\begin{tabular}{|c|c|c|c|c|c|c|}
\hline \multirow[t]{2}{*}{ Variable } & \multicolumn{2}{|c|}{ Malaria } & \multirow{2}{*}{$\begin{array}{l}\text { Number new } \\
\text { episodes }\end{array}$} & \multirow{2}{*}{$\begin{array}{l}\text { Crude incidence } \\
\text { rate ratio }\end{array}$} & \multirow[t]{2}{*}{$P$ value } & \multirow[t]{2}{*}{$95 \% \mathrm{Cl}$} \\
\hline & No & Yes & & & & \\
\hline \multicolumn{7}{|l|}{ Age } \\
\hline $0.5-1$ years & 31 & 37 & 65 & Reference & - & - \\
\hline$>1-5$ years & 121 & 123 & 272 & 0.85 & 0.397 & $0.590-1.233$ \\
\hline$>5-9$ years & 64 & 46 & 77 & 0.57 & $0.013^{*}$ & $0.371-0.887$ \\
\hline \multicolumn{7}{|l|}{ Blood group } \\
\hline$A+$ & 56 & 41 & 77 & Reference & - & - \\
\hline $\mathrm{B}+$ & 73 & 57 & 109 & 1.06 & 0.768 & $0.713-1.581$ \\
\hline $\mathrm{O}+$ & 78 & 87 & 184 & 1.38 & 0.086 & $0.955-2.000$ \\
\hline$A B+$ & 10 & 17 & 36 & 1.66 & 0.091 & $0.922-2.997$ \\
\hline $\mathrm{O}-$ & 1 & 1 & 4 & 2.49 & 0.306 & $0.433-14.340$ \\
\hline$B-$ & 0 & 1 & 1 & 1.24 & 0.878 & $0.074-20.906$ \\
\hline$A B-$ & 0 & 1 & 1 & 1.24 & 0.878 & $0.074-20.906$ \\
\hline \multicolumn{7}{|l|}{ Sickle cell genotype } \\
\hline Wild type & 158 & 145 & 289 & Reference & & \\
\hline Heterozygous & 64 & 46 & 110 & 0.78 & 0.394 & $0.755-1.427$ \\
\hline Malaria history & 201 & 199 & 412 & 7.33 & $0.008^{*}$ & $1.674-32.104$ \\
\hline Reported anti-malarial drug use & 206 & 197 & 386 & 1.68 & 0.247 & $0.698-4.043$ \\
\hline Reported ITN use & 184 & 189 & 377 & 2.69 & $0.001^{*}$ & $1.522-4.752$ \\
\hline
\end{tabular}


individuals. There was no difference in the distribution of malaria incidence across the RANTES -403G/A genotypes $(P=0.47)$. The adjusted incident rate for RANTES -403G/A heterozygotes was 1.09 times the incidence rate for wild-type individuals $(P=0.66)$. Similarly, homozygotes showed a non-significant trend towards higher incidence rates than those carrying the wild type genotype (IRR $=1.16 ; \mathrm{P}=0.50$ ) as shown in Table 5. Median parasite densities were as follows; wild type, 488 (IQR 213-2188) parasites/ $\mu \mathrm{L}$; heterozygote, 563 (IQR 200-2800) parasites/ $\mu$ L; homozygote, 825 (IQR 250-2450) parasites $/ \mu \mathrm{L}$. There was no difference in the geometric mean parasite densities between $-403 \mathrm{G} / \mathrm{A}$ heterozygotes and wild types $(\mathrm{P}=0.98)$ or between homozygotes and wild type individuals $(\mathrm{P}=0.82)$. Since the two markers $(-403 \mathrm{G} / \mathrm{A}$ and $\mathrm{In} 1.1 \mathrm{~T} / \mathrm{C})$ demonstrated a clear linkage disequilibrium, another multivariate analysis was done with linking markers. There was no statistically significant association between any combination of mutations with malaria incidence (Table 6).

\section{Effect of RANTES polymorphisms on time to first re-infection}

The impact of RANTES polymorphisms upon time to first re-infection after administration of malaria treatment was also evaluated. The average time (weeks) to first re-infection was 13.4 for RANTES In1.1T/C wildtype individuals, 12.7 for heterozygotes and 16.7 for homozygotes. There was no significant difference in the length of time to first re-infection between heterozygote and wild-type genotypes $(\mathrm{P}=0.74)$ or between homozygote and wild-type genotypes $(\mathrm{P}=0.34)$. After adjusting HRs for age, malaria history and ITN use, the hazard for re-infection did not differ significantly between heterozygotes and wild-type genotypes $(\mathrm{HR}=1.19 ; \mathrm{P}=0.28)$ or between the In1.1C homozygotes and wildtypes $(\mathrm{HR}=1.2 ; \mathrm{P}=0.67)$ (Fig. 3).

The average time (weeks) to first re-infection was 10.8 for RANTES -403 G/A wild-type individuals, 13.4 for heterozygotes and 11.4 for homozygotes. The was no difference in the length of time to first re-infection between heterozygotes and wild-type genotypes $(\mathrm{P}=0.29)$ or between homozygotes and wild-type individuals $(\mathrm{P}=0.44)$. Additionally, no significant difference was seen in the hazard for re-infection for wild types vs heterozygotes $(\mathrm{HR}=1.31 ; \mathrm{P}=0.21)$ or between the wildtypes and $-403 \mathrm{~A}$ homozygotes $(\mathrm{HR}=1.22 ; \mathrm{P}=0.42)$ (Fig. 4).

\section{Discussion}

In this study, the relationship between the presence of mutations in RANTES and incidence of malaria in a cohort of children living in a malaria-endemic area

Table 5 Effect of RANTES polymorphisms on incidence of malaria

\begin{tabular}{|c|c|c|c|c|c|c|c|c|}
\hline \multirow[t]{2}{*}{ RANTES genotype } & \multicolumn{2}{|c|}{ Malaria } & \multirow{2}{*}{$\begin{array}{l}\text { Number new } \\
\text { episodes }\end{array}$} & \multirow{2}{*}{$\begin{array}{l}\text { Adjusted incidence } \\
\text { rate ratio }\end{array}$} & \multirow[t]{2}{*}{$P$} & \multirow[t]{2}{*}{$95 \% \mathrm{Cl}$} & \multirow{2}{*}{$\begin{array}{l}\text { Median } \\
\text { parasite density }\end{array}$} & \multirow[t]{2}{*}{$P$} \\
\hline & No & Yes & & & & & & \\
\hline \multicolumn{9}{|l|}{ RANTES 403G/A } \\
\hline GG & 42 & 34 & 63 & Reference & - & - & 488 & Reference \\
\hline GA & 108 & 117 & 240 & 1.09 & 0.664 & $0.744-1.590$ & 563 & 0.981 \\
\hline AA & 57 & 49 & 103 & 1.16 & 0.500 & $0.753-1.788$ & 825 & 0.815 \\
\hline \multicolumn{9}{|l|}{ RANTES In $1.1 T / C$} \\
\hline $\mathrm{TT}$ & 143 & 122 & 240 & Reference & - & - & 775 & Reference \\
\hline TC & 63 & 62 & 118 & 1.10 & 0.344 & $0.804-1.506$ & 373 & 0.258 \\
\hline CC & 9 & 6 & 11 & 1.25 & 0.560 & $0.541-2.888$ & 2450 & 0.166 \\
\hline
\end{tabular}

${ }^{a}$ Median parasite density (parasites $/ \mu \mathrm{L}$ ) at the time of diagnosis of symptomatic malaria

Table 6 RANTES In 1.1/403 compound genotypes and malaria incidence

\begin{tabular}{|c|c|c|c|c|c|c|}
\hline \multirow{2}{*}{$\begin{array}{l}\text { RANTES In } 1.1 / 403 \\
\text { genotype }\end{array}$} & \multicolumn{2}{|c|}{ Malaria } & \multirow{2}{*}{$\begin{array}{l}\text { No. of new } \\
\text { episodes }\end{array}$} & \multirow{2}{*}{$\begin{array}{l}\text { Adjusted incident } \\
\text { rate ratio }\end{array}$} & \multirow[t]{2}{*}{ P value } & \multirow[t]{2}{*}{$95 \% \mathrm{Cl}$} \\
\hline & No & Yes & & & & \\
\hline$w t / w t$ & 42 & 33 & 61 & Reference & - & - \\
\hline het/het & 36 & 43 & 89 & 0.731 & 0.162 & $0.472-1.133$ \\
\hline het/hom & 25 & 18 & 28 & 1.171 & 0.609 & $0.640-2.142$ \\
\hline hom/hom & 8 & 6 & 11 & 0.935 & 0.879 & $0.394-2.220$ \\
\hline
\end{tabular}




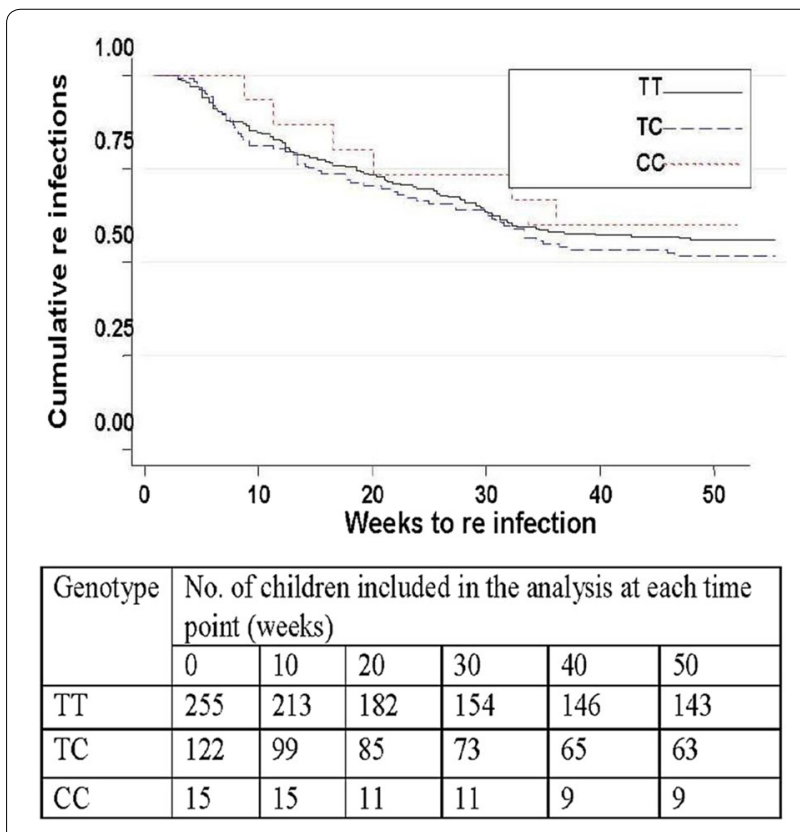

Fig. 3 Kaplan-Meier plots for re infection by RANTES INT1.1 genotype (TT, TC or CC). Cumulative re-infections are plotted against weeks to the next infection. The study participants were actively followed-up with visits once every 2 weeks at their homes, to obtain information about re-infection. Using a Cox proportion hazard regression model, adjusting for age, malaria history and ITN use, the predictors of length of time to first re-infection for TT (wild- type); TC (heterozygous) and CC (homozygous) were not statistically different with $p$-value of 0.28 and 0.67 , respectively

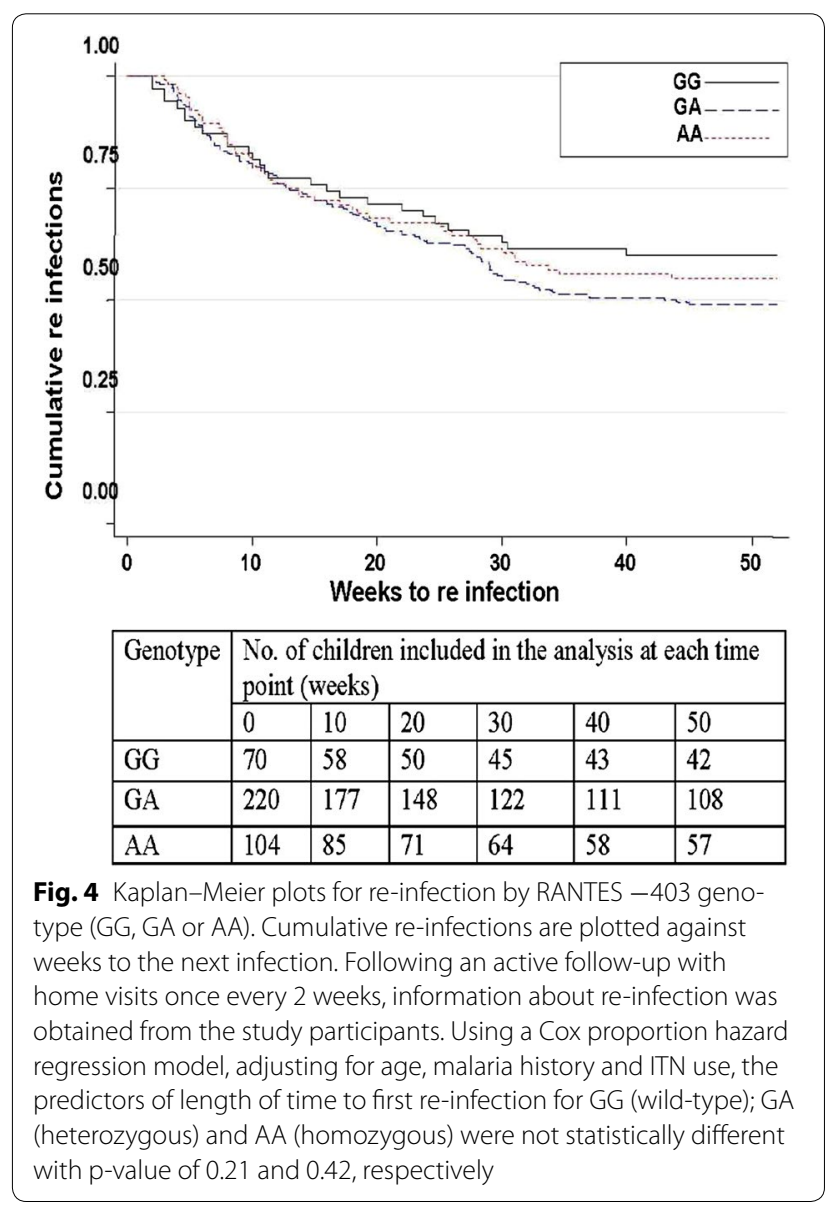

[31] and Han Chinese populations [23], but scarcely distributed among Caucasian, African American [22] and Ugandan populations [30]. In this study, no mutations were found at the $-28 \mathrm{C}$ loci consistent with studies conducted elsewhere [22].

The In1.1C allele, which occurs in strong linkage disequilibrium with the $-403 \mathrm{~A}$ allele, has been shown to lead to down-regulation of RANTES and lower levels of the cytokine $[22,23]$. Low levels of RANTES have previously been associated with severe malaria [11, 12], but no direct relation with any incidence of malaria was seen before. In the present study, none of the RANTES mutations investigated showed any significant effect on malaria incidence, baseline parasite densities or time to first re-infection. In that context, the high frequency of the -403 mutation is surprising, since, as with many other polymorphisms such as sickle cell trait, malaria is cited as a factor that selects for a disease-related gene variant $[5,6]$. Of course, RANTES is important in many other infections as well, but it is still hard to explain that lower levels of a chemokine could possibly be protective against common infections. The third marker, at -28 , was found to be wild type in all children included in the other populations in different study settings [22]. The rare $-28 \mathrm{G}$ allele is found predominantly among Japanese 
present study. Absence of the -28 mutation, is a little surprising. This mutation up-regulates expression [22, 23], and would confer better protection. However, higher levels of RANTES may be detrimental for other reasons [32]. This is also in line with high prevalence of the -403 mutation, which reduces RANTES levels. Other studies confirm the higher incidence of the -403 mutation in African populations [22, 28, 30] and could indicate a selective force for low levels of RANTES. This is also consistent with other reports in which lower levels of RANTES have been observed in African populations compared to other populations [32]. Given the role of RANTES in protection against infectious diseases, these findings remain hard to explain.

In other disease conditions such as HIV where RANTES polymorphisms have been studied, there are still contrasting reports on the influence of these variants on susceptibility and disease progression. The strong down-regulatory activity on RANTES transcription that is afforded by -403 and In1.1 mutations has been shown to lead to increased susceptibility to HIV infection [29] and increased rate of disease progression [22, 48]. In other studies, no associations between these variants and HIV infection could be observed [28] and elsewhere, In1.1C homozygosity was associated with delayed disease progression among adult HIV-positive patients [30]. These findings suggest that the role of these variants in determining disease susceptibility and clinical outcomes in different study settings is still not clearly understood. Other markers within the RANTES gene that could potentially modulate RANTES expression may need to be evaluated in order to understand the observable differences in epidemiological patterns. This may provide an insight into a clearer understanding of the role of RANTES polymorphisms in other diseases like malaria.

In the present study, previous history of malaria prior to recruitment was recorded as well. Most children reported previous experience of malaria, and these showed a higher incidence rate than those who were earlier free from the disease. These findings may suggest a genetic basis for susceptibility to malaria, which of course is most likely multifactorial, and dependent on other markers besides RANTES. A small number of children had many episodes of malaria during the study, up to nine during 1 year. At each incidence, the children were treated and cured from malaria, but they obviously get re-infected rapidly, and obviously do not develop protective immunity. At the same time, many children stayed free from malaria for the whole year, and the majority of those with malaria had only one episode. These children live under very similar conditions, so they should be exposed to infectious mosquito bites at similar rates. In this study, there was no significant relation between the
RANTES polymorphisms and malaria incidence. Given that malaria susceptibility involves a complex interplay of other genetic modifiers, such as sickle cell trait, G6PD deficiency, among others $[5,6]$, the impact of RANTES polymorphisms alone on malaria incidence may not be evident. Sickle cell heterozygotes showed lower incidence of malaria compared to those with normal haemoglobin. The $\mathrm{O}+$ blood group type known for protection against severe $P$. falciparum malaria $[51,52]$ instead showed a trend towards higher incidence of malaria, a variation that may relate to differences in the impact of the $\mathrm{O}+$ blood group type upon severe malaria rather than the actual susceptibility to malaria. Controlling for these factors still yielded no significant associations between the RANTES polymorphisms and malaria incidence. Thus, additional studies evaluating other markers that could potentially modify RANTES gene expression alongside other biological interactions between other genetic modifiers and their impact on malaria susceptibility may provide a clearer understanding of these less dramatic associations.

There were some limitations to this study. Information on known preventive measures and prior anti-malarial drug use was obtained by questionnaire-based interviews, which could have influenced the outcome of the multivariate analysis since known protective measures unexpectedly scored as risk factors of malaria. Additionally, this study looked at a single gene (RANTES). Additional modifying genetic factors other than the sickle cell trait were not adjusted for.

\section{Conclusions}

Results of this study show that the $-403 \mathrm{~A}$ mutation occurs in nearly half the study population and In1.1C allele occurs in one in every four children. Despite the high frequency of these mutations, there was no clear association with malaria incidence. Since both polymorphisms lead to down-regulation of RANTES expression and expected lower levels of RANTES, these findings remain hard to explain. There were no mutations at the -28 marker. This marker has previously been shown to lead to increased RANTES expression. Thus, absence of -28 mutation in the Uganda study population is quite surprising. Evaluating other markers that could potentially modulate RANTES gene transcription may provide further explanations to these less dramatic findings. Additionally, since there are several other markers that have been implicated in pathogenesis of malaria, the impact of RANTES polymorphisms alone on malaria incidence may be difficult to evaluate. Therefore, other larger studies looking at the interplay between other genetic modifiers and malaria susceptibility may provide clearer understanding of these findings. 


\section{Abbreviations}

IFN- $\gamma$ : interferon-gamma; TNF: tumor necrosis factor; IL-10: interleukin-10; IL-17: interleukin-17; IL-4: interleukin-4; RANTES: regulated upon activation, normal T cell expressed and secreted; MMP8 s: matrix metalloproteinases 8; TIMP1: tissue inhibitor of metalloproteinases 1; SNP: single nucleotide polymorphism; HIV: human immunodeficiency virus; AIDS: acquired immuno deficiency syndrome; WHO: World Health Organization; EIR: entomological innoculation rate; WBC: white blood cells; EDTA: ethylene diamine tetraacetic acid; DNA: deoxyribonucleic acid; PCR: polymerase chain reaction; RFLP: restriction fragment length polymorphism; IRR: incident rate ratio; IQR: inter quartile range; HR: hazard ratio; ITN: insecticide treated bed net; ANOVA: analysis of variance.

\section{Authors' contributions}

$\mathrm{CL}$ participated in study design, data collection and laboratory analysis. MK participated in patient recruitment and data collection. GS and FK conceived the study, supervised data collection and ensured quality of the laboratory results. All authors participated in the writing and review of the manuscript. All authors read and approved the final manuscript.

\section{Author details}

1 School of Biomedical Sciences, College of Health Sciences, Makerere University, PO Box 7072, Kampala, Uganda. ${ }^{2}$ School of Medicine, College of Health Sciences, Makerere University, Kampala, Uganda. ${ }^{3}$ Department of Medical Biochemistry and Microbiology, Uppsala University, Uppsala, Sweden. ${ }^{4}$ Faculty of Health Sciences, Habib Medical School, Islamic University in Uganda (IUIU), Kampala Campus, Kampala, Uganda.

\section{Acknowledgements}

We are grateful to the Iganga cohort children, parents and guardians for allowing participation in the study. We thank the clinical team, Monika Somberg and all members from the Malaria Subprogram at the Department of Biochemistry, Mulago Hospital for technical support. Special thanks to Levi Mugenyi for his guidance in the statistical analysis and Steven Kiwuwa for thorough reading of the manuscript. The research leading to these results has received funding from the European Community's Seventh Framework Programme (FP7/2007-2013) under Grant agreement No 242095 (EVIMA$L A R)$. We wish to acknowledge the financial support received from research collaborations under Sida/SAREC - Makerere University-Karolinska Institutet and Uppsala Universitet. We appreciate the financial support of the European and Developing Countries Clinical Trials Partnership (EDCTP) received under Grant no. IP.2007.3110.001.

\section{Compliance with ethical guidelines}

\section{Competing interests}

The authors declare that they have no competing interests.

Received: 17 April 2015 Accepted: 27 August 2015

Published online: 05 September 2015

\section{References}

1. WHO. World malaria report 2014. Geneva: World Health Organization; 2014.

2. Doolan DL, Doban C, Baird JK. Acquired immunity to malaria. Clin Microbiol Rev. 2009;22:13-36.

3. Taylor SM, Parobek CM, Fairhurst RM. Haemoglobinopathies and the clinical epidemiology of malaria: a systematic review and meta-analysis. Lancet Infect Dis. 2012;12:457-68.

4. Lopera-Mesa TM, Doumbia S, Konate D, Anderson JM, Doumbouya M, Keita AS, et al. Impact of red blood cell variants on childhood malaria in Mali: a prospective cohort study. Lancet Haematol. 2015;2:e140-9.

5. de Mendonca VR, Goncalves MS, Barral-Netto M. The host genetic diversity in malaria infection. J Trop Med. 2012;2012:940616.

6. Driss A, Hibbert JM, Wilson NO, lqbal SA, Adamkiewicz TV, Stiles JK. Genetic polymorphisms linked to susceptibility to malaria. Malar J. $2011 ; 10: 271$.
7. Mackinnon MJ, Mwangi TW, Snow RW, Marsh K, Williams TN. Heritability of malaria in Africa. PLoS Med. 2005;2:e340.

8. Gong L, Maiteki-Sebuguzi C, Rosenthal PJ, Hubbard AE, Drakeley CJ, Dorsey $\mathrm{G}$, et al. Evidence for both innate and acquired mechanisms of protection from Plasmodium falciparum in children with sickle cell trait. Blood. 2012;119:3808-14.

9. Day NP, Hien TT, Schollaardt T. The prognostic and pathophysiologic role of pro- and anti-inflammatory cytokines in severe malaria. J Infect Dis. 1999;180:1288-97.

10. Dodoo D, Omer FM, Todd J, Akanmori BD, Koram KA, Riley EM. Absolute levels and ratios of pro-inflammatory and anti-inflammatory cytokine production in vitro predict clinical immunity to Plasmodium falciparum malaria. J Infect Dis. 2002:185:971-9.

11. Were T, Hittner JB, Ouma C, Otieno RO, Orago ASS, Ong'echa JM, et al. Suppression of RANTES in children with Plasmodium falciparum malaria. Haematologica. 2006;91:1396-9.

12. John CC, Opika-Opoka R, Byarugaba J, Idro R, Boivin MJ. Low levels of RANTES are associated with mortality in children with cerebral malaria. J Infect Dis. 2006;194:837-45.

13. Dietmann A, Helbok R, Lackner P, Issifou S, Lell B, Matsiegui PB, et al. Matrix metalloproteinases and their tissue inhibitors (TIMPs) in Plasmodium falciparum malaria: serum levels of TIMP-1 are associated with disease severity. J Infect Dis. 2008;197:1614-20.

14. Perera MK, Herath NP, Pathirana SL, Phone-Kyaw M, Alles HK, Mendis KN, et al. Association of high plasma TNF-alpha levels and TNF-alpha/IL-10 ratios with TNF2 allele in severe $P$. falciparum malaria patients in Sri Lanka. Pathog Glob Health. 2013;107:21-9.

15. Mahanta A, Kar SK, Kakati S, Baruah S. Heightened inflammation in severe malaria is associated with decreased IL-10 expression levels and neutrophils. Innate Immun. 2015;21:546-52.

16. Tangteerawatana P, Krudsood S, Kanchanakhan N, Troye-Blomberg $\mathrm{M}$, Khusmith S. Low monocyte to neutrophil ratio in peripheral blood associated with disease complication in primary Plasmodium falciparum infection. Southeast Asian J Trop Med Public Health. 2014;45:517-30.

17. Luster AD. The role of chemokines in linking innate and adaptive immunity. Curr Opin Immunol. 2002;14:129-35.

18. Majka M, Janowska-Wieczorek A, Ratajczak J, Ehrenman K, Pietrzkowski Z, Kowalska MA, et al. Numerous growth factors, cytokines, and chemokines are secreted by human CD34+ cells, myeloblasts, erythroblasts, and megakaryoblasts and regulate normal hematopoiesis in an autocrine/ paracrine manner. Blood. 2001;97:3075-85.

19. Ochiel DO, Gordon A, Keller CC, Hittner JB, Kremsner PG, Weinberg JB, et al. Differential regulation of $\beta$-chemokines in children with Plasmodium falciparum malaria. Infect Immun. 2005;73:4190-7.

20. Sarfo BY, Armah HB, Irune I, Adjei AA, Olver CS, Singh S, et al. Plasmodium yoelii 17XL infection upregulates RANTES, CCR1, CCR3, and CCR5 expression, and it induces ultrastructural changes in the cerebellum. Malar J. 2005;4:63.

21. Wright DE, Bowman EP, Wagers AJ, Butcher EC, Weissman IL. Hematopoietic stem cells are uniquely selective in their migratory response to chemokines. J Exp Med. 2002;195:1145-54.

22. An P, Nelson GW, Wang L, Donfield S, Goedert JJ, Phair J, et al. Modulating influence on HIV/AIDS by interacting RANTES gene variants. Proc Natl Acad Sci USA. 2002;99:10002-7.

23. Liu H, Chao D, Nakayama EE, Taguchi H, Goto M, Xin X, et al. Polymorphism in RANTES chemokine promoter affects HIV-1 disease progression. Proc Natl Acad Sci USA. 1999;96:4581-5.

24. Were T, Davenport GC, Yamoa EO, Hittnerd JB, Awandare GA, Otieno MF, et al. Naturally-acquired hemozoin by monocytes promotes suppression of RANTES in children with malarial anemia through an IL-10-dependent mechanism. Microbes Infect. 2009;11:811-9.

25. McDermott DH, Beecroft MJ, Kleeberger CA, Al-Sharif FM, Ollier WE, Zimmerman PA, et al. Chemokine RANTES promoter polymorphism affects risk of both HIV infection and disease progression in the Multicentre AIDS Cohort Study. AIDS. 2000;14:2671-8.

26. Wichukchinda N, Nakayama EE, Rojanawiwat A, Pathipvanich P, Auwanit W, Vongsheree S, et al. Protective effects of IL4-589T and RANTES -28G on HIV-disease progression in infected Thai females. AIDS. 2006;20:189-96.

27. Koizumi Y, Kageyama S, Fujiyama Y, Miyashita M, Lwembe R, Ogino K, et al. RANTES -28G delays and DC-SIGN -139C enhances AIDS progression in 
HIV type 1-infected Japanese hemophiliacs. AIDS Res Hum Retroviruses. 2007;23:713-9.

28. Gonzalez E, Dhanda R, Bamshad M, Mummidi S, Geevarghese R, Catano G, et al. Global survey of genetic variation in CCR5, RANTES, and MIP1alpha: impact on the epidemiology of the HIV-1 pandemic. Proc Natl Acad Sci USA. 2001;98:5199-204.

29. Zhao XY, Lee SS, Wong KH, Chan KC, Ma S, Yam WC, et al. Effects of single nucleotide polymorphisms in the RANTES promoter region in healthy and HIV-infected indigenous Chinese. Eur J Immunogenetics. 2004;31:179-83.

30. Cooke GS, Kerrie T, Ramaley PA, Kaleebu P, Zhuang J, Nakiyingi JS, et al. A polymorphism that reduces RANTES expression is associated with protection from death in HIV-seropositive Ugandans with Advanced disease. J Infect Dis. 2006;194:666-9.

31. Paxton WA, Neumann AU, Kang S, Deutch L, Brown RC, Koup RA, et al. RANTES production from CD4+ lymphocytes correlates with host genotype and rates of human immunodeficiency virus type 1 disease progression. J Infect Dis. 2001;183:1678-81.

32. Virani SS, Nambi V, Hoogeveen R, Wasserman BA, Coresh J, Gonzalez F, et al. Relationship between circulating levels of RANTES (regulated on activation, normal T-cell expressed, and secreted) and carotid plaque characteristics: the Atherosclerosis Risk in Communities (ARIC) Carotid MRI Study. Eur Heart J. 2011;32:459-68.

33. Liao CH, Yao TC, Chung HT, See LC, Kuo ML, Huang JL. Polymorphisms in the promoter region of RANTES and the regulatory region of monocyte chemo attractant protein-1 among Chinese children with systemic lupus erythematosus. J Rheumatol. 2004;31:2062-7.

34. Yao TC, Kuo ML, See LC, Chen LC, Yan DC, Ou LS, Shaw CK, Huang JL. The RANTES promoter polymorphism: a genetic risk factor for near-fatal asthma in Chinese children. J Allergy Clin Immunol. 2003;111:1285-92.

35. Nickel RG, Casolaro V, Wahn U, Beyer K, Barnes KC, Plunkett BS, et al. Atopic dermatitis is associated with a functional mutation in the promoter of the C-C chemokine RANTES. J Immunol. 2000;164:1612-6.

36. Tanaka KR, Roberts MH, Yamamoto N, Sugiura H, Uehara M, Hopkin JM. Upregulating promoter polymorphisms of RANTES relate to atopic dermatitis. Int J Immunogenet. 2006;33:423-8.

37. Nakajima K, Tanaka Y, Nomiyama T, Ogihara T, Ikeda F, Kanno R, et al. RANTES promoter genotype is associated with diabetic nephropathy in type 2 diabetic subjects. Diabetes Care. 2003;26:892-8.

38. Simeoni E, Winkelmann BR, Hoffmann MM, Fleury S, Ruiz J, Kappenberger $L$, et al. Association of RANTES G-403A gene polymorphism with increased risk of coronary arteriosclerosis. Eur Heart J. 2004;25:143846.
39. Krüger B, Boger CA, Obed A, Farkas S, Hoffmann U, Banas B, et al. RANTES/ CCL5 polymorphisms as a risk factor for recurrent acute rejection. Clin Transplant. 2007;21:385-90.

40. Dossou-Yovo OP, Zaccaria I, Benkerrou M, Hauchecorne M, Alberti C, Rahimy MC, et al. Effects of RANTES and MBL2 gene polymorphisms in sickle cell disease clinical outcomes: association of the g.In $1.1 \mathrm{~T}>\mathrm{C}$ RANTES variant with protection against infections. Am J Hematol. 2009;84:378-80.

41. Ministry of Health. Uganda malaria indicator survey 2009. 2010. p. 1-3.

42. Okello PE, Van Bortel W, Byaruhanga AM, Correwyn A, Roelants P, Talisuna $A$, et al. Variation in malaria transmission intensity in seven sites throughout Uganda. Am J Trop Med Hyg. 2006;75:219-25.

43. de Onis M, Onyango AW, Borghi E, Garza C, Yang H. WHO Multicentre Growth Reference Study Group: comparison of the World Health Organization Child Growth Standards and the National Center for Health Statistics/WHO international growth reference: implications for child health programmes. Public Health Nutr. 2006;9:942-7.

44. WHO. Basic malaria microscopy Part I Learner's guide. 2nd ed. Geneva: World Health Organization; 2010. p. 74-5.

45. WHO. Communicable diseases cluster: severe falciparum malaria. Trans R Soc Trop Med Hyg. 2009;94(Suppl 1):S1-90

46. Bejon P, Berkley JA, Mwangi T, Ogada E, Mwangi I, Maitland K, et al. Defining childhood severe falciparum malaria for intervention studies. PLoS Med. 2007:4:e251.

47. Hajeer AH, Al Sharif F, Ollier WER. A polymorphism at position -403 in the human RANTES promoter. Eur J Immunogenet. 1999;26:375-6.

48. Rathore A, Chatterjee A, Sivarama P, Yamamoto N, Singhal PK, Dhole TN. Association of RANTES $403 \mathrm{G} / \mathrm{A}, 28 \mathrm{C} / \mathrm{G}$ and $\ln 1.1 \mathrm{~T} / \mathrm{C}$ Polymorphism With HIV-1 Transmission and Progression Among North Indians. J Med Virol. 2008;80:1133-41.

49. Parikh S, Dorsey G, Rosenthal PJ. Host polymorphisms and the incidence of malaria in Ugandan children. Am J Trop Med Hyg. 2004;71:750-3.

50. McClean P. Population and evolutionary genetics. 1998. https://www. ndsu.edu/pubweb/ mcclean/plsc431/popgen/popgen4.htm.

51. Panda AK, Panda SK, Sahu AN, Tripathy R, Ravindran B, Das BK. Association of $A B O$ blood group with severe falciparum malaria in adults: case control study and meta-analysis. Malar J. 2011;10:309.

52. Rowe JA, Handel IG, Thera MA, Deans AM, Lyke KE, Kone A, et al. Blood group O protects against severe Plasmodium falciparum malaria through the mechanism of reduced rosetting. Proc Natl Acad Sci USA. 2007;104:17471-6.

\section{Submit your next manuscript to BioMed Central and take full advantage of:}

- Convenient online submission

- Thorough peer review

- No space constraints or color figure charges

- Immediate publication on acceptance

- Inclusion in PubMed, CAS, Scopus and Google Scholar

- Research which is freely available for redistribution

Submit your manuscript at

www.biomedcentral.com/submit

C Biomed Central 